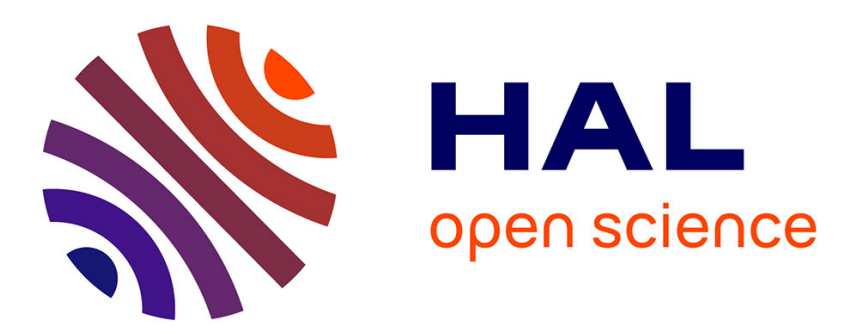

\title{
Solution structures of important multidomain proteins of the complement system by X-ray and neutron scattering
}

\author{
S. Perkins, A. Nealis, K. Smith, R. Sim
}

\section{To cite this version:}

S. Perkins, A. Nealis, K. Smith, R. Sim. Solution structures of important multidomain proteins of the complement system by X-ray and neutron scattering. Journal de Physique IV Proceedings, 1993, 03 (C8), pp.C8-261-C8-264. 10.1051/jp4:1993851 • jpa-00252282

\section{HAL Id: jpa-00252282 https://hal.science/jpa-00252282}

Submitted on 1 Jan 1993

HAL is a multi-disciplinary open access archive for the deposit and dissemination of scientific research documents, whether they are published or not. The documents may come from teaching and research institutions in France or abroad, or from public or private research centers.
L'archive ouverte pluridisciplinaire HAL, est destinée au dépôt et à la diffusion de documents scientifiques de niveau recherche, publiés ou non, émanant des établissements d'enseignement et de recherche français ou étrangers, des laboratoires publics ou privés. 


\title{
Solution structures of important multidomain proteins of the complement system by $X$-ray and neutron scattering
}

\author{
S.J. PERKINS, A.S. NEALIS, K.F. SMITH and R.B. SIM*
}

Department of Biochemistry and Chemistry, Royal Free Hospital, School of Medicine, Rowland Hill Street, London NW3 $2 P F$, U.K.

${ }^{*}$ MRC Immunochemistry Unit, Department of Biochemistry, South Parks Road, Oxford OX1 3QU, U.K.

\section{ABSTRACT}

The complement proteins constitute a family of large multidomain proteins with generally unknown solution structures. Solution scattering offers a powerful means of determining these solution structures, particularly when combined with the results from electron microscopy and/or analytical ultracentrifugation and also with known atomic structures for individual domains in these proteins. This method has been applied to 13 of the 18 soluble complement proteins. While many of them have highly extended structures, others have relatively compact structures. To facilitate studies of the multidomain serine proteases of complement, scattering analyses of $\beta-$ trypsin and $\alpha$-chymotrypsin and their proenzymes were carried out, and their scattering properties were well-reproduced by reference to their crystal structures. Factor $I$ has a five-domain structure that includes a serine protease-like domain. Its overall length of $13 \mathrm{~nm}$ from scattering is too short to allow for a highly extended solution structure of domains, and scattering curve fits were best achieved by arranging these domains into a more compact form. In terms of the functional role of factor $I$, its domains appear to have a restricted surface accessibility for interactions with its substrates.

\section{INTRODUCTION}

The complement cascade is a family of 20-40 soluble and membranebound proteins that plays a crucial role in the immune system [1]. On activation, the cascade leads to the formation of protein complexes that penetrate membranes and cause cellular death. Almost all the complement components are multidomain proteins [2]. These are difficult (if not impossible) to crystallize, so structural studies therefore have to proceed at two levels:

(a) determination of the overall arrangement of domains in solution; (b) determination of the detailed molecular structure of each domain.

Neutron and $\mathrm{X}$-ray solution scattering is a powerful means of determining the overall arrangement of domains in the complement proteins under near-physiological conditions [3]. In particular it offers strongly complementary advantages to electron microscopy and scanning tunnelling microscopy in that the macromolecules are seen in 3-D in solution, and not when flattened onto a 2-D template. The structural analyses often reveal unexpected domain arrangements. The 
increasing availability of atomic structures for individual domains from crystallography and/or 2D-NMR, together with accurate sequence data, has given new impetus to this technique. The constrained assembly of known atomic structures for each domain using molecular graphics in order to create models for the full macromolecular structure can be used to calculate scattering curve fits and the determination of the overall macromolecular structure in solution. This article summarises the current status of scattering studies on the complement proteins, together with an analysis of factor $I$.

\section{X-RAY AND NEUTRON SCATTERING OF SERINE PROTEASES}

The serine protease domain is central to all proteolytic events during complement activation. As models of this domain, bovine $\beta-$ trypsin, trypsinogen, $\alpha$-chymotrypsin and chymotrypsinogen $A$ were studied by neutron and $\mathrm{X}$-ray synchrotron solution scattering [5]. The $X-r a y$ and neutron radil of gyration $R_{G}$ of these four proteins were compared with those calculated using crystallographic coordinates to assess critically how accurate the solution scattering parameters can be determined. For example, the experimental $R_{G}$ values at infinite neutron scattering contrast were $1.57 \mathrm{~nm}, 1.70 \mathrm{~nm}, 1.67 \mathrm{~nm}$ and 1.78 $\mathrm{nm}$ for $\beta$-trypsin, trypsinogen, $\alpha$-chymotrypsin and chymotrypsinogen $A$ in that order (errors $\pm 0.03 \mathrm{~nm}$ ). The calculated $R_{G}$ values from the crystal structures were in good agreement to within $0.1 \mathrm{~nm}$ at $1.65 \mathrm{~nm}$, $1.72 \mathrm{~nm}, 1.66 \mathrm{~nm}$ and $1.70 \mathrm{~nm}$ respectively. The full $\mathrm{x}$-ray and neutron scattering curves in positive and negative contrasts agreed well with the calculated curves from crystallographic coordinates to a nominal structural resolution of $4.5 \mathrm{~nm}$, provided that the internal structure was considered in neutron modeling, and that the hydration was considered in $\mathrm{X}$-ray modelling.

$\mathrm{X}$-ray scattering on the single-domain complement serine protease factor $D$ (FD) showed from its $R_{G}$ of $1.78 \mathrm{~nm}$ that this is monomeric and very similar in structure to $\beta$-trypsin [5]. The $X$-ray scattering curve of factor $D$ was readily modelled using the $\beta$-trypsin crystal structure after allowance for sequence insertions and deletions.

\section{X-RAY AND NEUTRON SCATTERING OF FACTOR I}

Factor I (FI) is a typical multidomain protein of complement, and is constructed from five domains, namely a factor I module, a CD5-like domain, two LDL receptor type A domains and a serine protease domain. $\mathrm{X}$-ray and neutron solution scattering was used to study the arrangement of these domains in factor $I$ [6]. Its $R_{G}$ was $3.96 \mathrm{~nm}$ by $x$-rays and $3.84 \mathrm{~nm}$ by neutrons at infinite solute-solvent contrast. The cross-sectional radius of gyration $R_{X S}$ was likewise found to be $1.64 \mathrm{~nm}$ by $\mathrm{x}$-rays and $1.55 \mathrm{~nm}$ by neutrons. The maximum dimension of factor I was determined to be $12.8 \mathrm{~nm}$ from the $R_{G}$ and $R_{X S}$ data, and 14-15 nm from the $\mathrm{X}$-ray and neutron distance distribution functions.

Small sphere models were developed for factor I in which the largest domain was modelled starting from the crystal structure for $\beta$-trypsin. The length of $12.8 \mathrm{~nm}$ is too short to account for a linear arrangement of the domains in factor $I$, and more compact arrangements have to be considered. The attachment of such structures to the serine protease domain to represent the remaining four small domains gave good scattering curve fits for factor I (Figure 1). The non-extended domain models for factor I imply that under physiological conditions the steric accessibility of each domain will be reduced, and this may be important for the functional activity of factor I. 


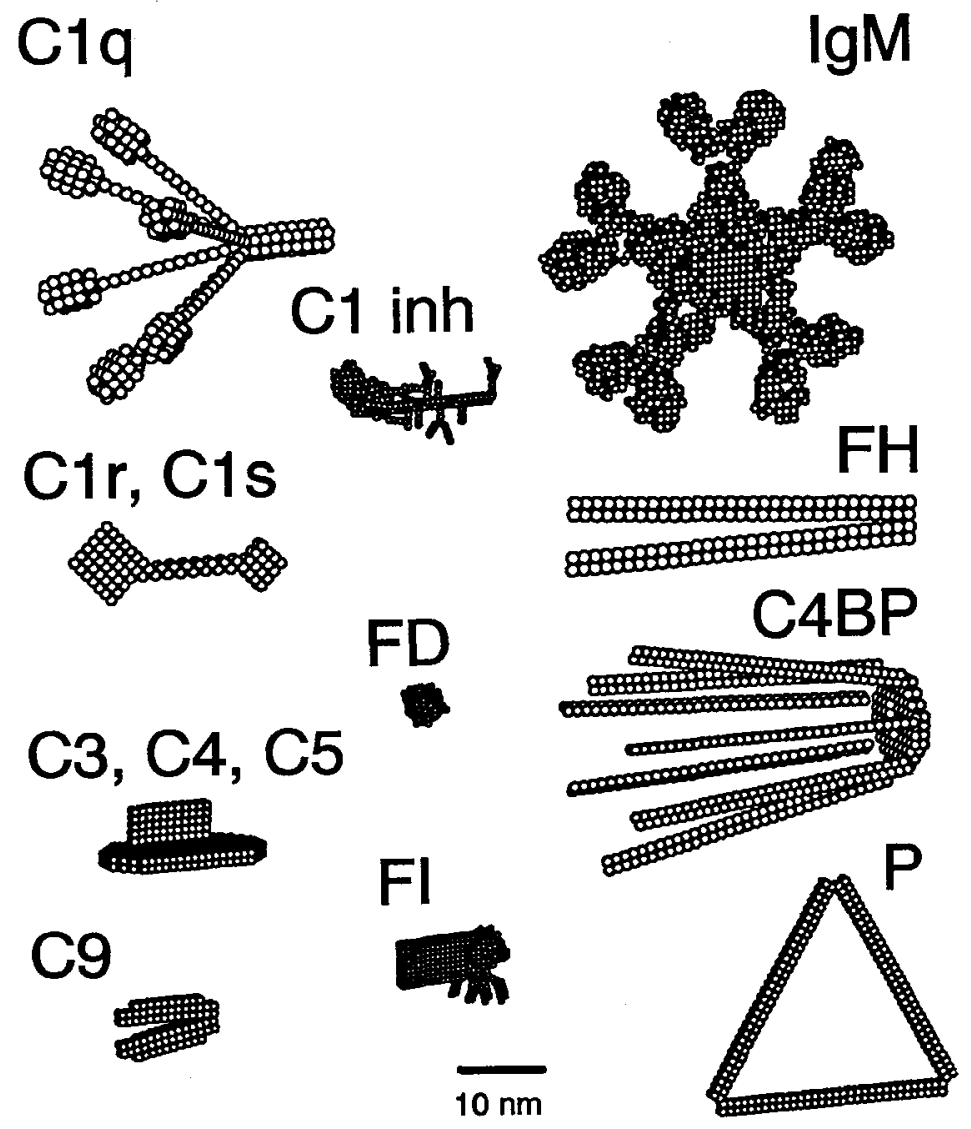

Figure 1. Summary of the solution scattering models determined for 13 of the 18 major complement components, together with immunoglobulin M. All are drawn to the same scale. Molecular weights range from 24,400 (FD) to 966,000 (IgM); all are monomeric proteins in solution. Carbohydrate residues were modelled explicitly in $\mathrm{C} 1$ inh and $\mathrm{FI}$.

OTHER SCATTERING STUDIES ON MULTIDOMAIN PROTEINS IN COMPLEMENT

Three experimental strategies for interpretation of scattering data for the complement proteins have been followed:

(a) No atomic structure is available, but electron microscopy (EM) and hydrodynamic sedimentation coefficients $\mathbf{s}_{20}^{\circ}, \mathrm{w}$ are available as independent controls of the scattering analyses. This was the situation for $\mathrm{C} 3, \mathrm{C} 4, \mathrm{C} 5, \mathrm{C} 4 \mathrm{~b}$ binding protein (C4BP), factor $\mathrm{H}(\mathrm{FH})$, properdin (P), and $C 9$ [3]. In such cases, the known amino acid sequence and estimated carbohyrate content from DNA sequencing was used to define the volume of the glycoprotein from standard residue volumes [7]. The appropriate total of small spheres of the same volume was then used to construct general ellipsoids or rods that accounted for the macromolecular dimensions observed by solution scattering. 
(b) An atomic structure is available for a significant part of the macromolecule, together with EM and $s_{20}^{\circ}$ wata, as illustrated above for factor I [6]. Other examples include $C 1$ inhibitor (C1 inh) (where the crystal structure of the SERPIN fold in $\alpha_{1}$-antitrypsin was used with the scattering data to model the unknown structure of the large $\mathbf{N}$-terminal domain attached to this SERPIN domain in C1 inhibitor [8]), Clq (where the known dimensions of the collagen triple helix provided the constraint for the neutron scattering analyses) and C1r and C1s (which also contain serine protease domains) [3].

(c) Atomic structures are available for all the domains in the macromolecule, as well as EM and $s_{20}, w$ data. This was applied to analyse the 71 immunoglobulin folds in immunoglobulin $M$ (IgM). Molecular graphics was used to assemble sterically correct models for these domains in IgM and four proteolytically-cleaved or reduced fragments of IgM. These models could then be refined against the synchrotron X-ray data [4]. Factor D was analysed by this means [5].

\section{CONCLUSIONS}

Scattering studies have been completed for 13 of the 18 soluble complement proteins, and are in progress on the remaining ones. Many of these have extended solution structures with highly exposed domain surfaces for protein-protein interactions. Others have more compact domain structures. For the latter, the steric accessibilities of the domains may be important in complement activation and control.

For these studies, it is important to include other evidence from EM and $s_{20}^{\circ}$, experiments and to employ protein crystal and $2 \mathrm{D}-\mathrm{NMR}$ structures wherever appropriate. Likewise careful scattering data analyses are required. Controls are provided by molecular weight calculations from $I(0) / C$ data, and the joint complementary use of neutron and $\mathrm{X}$-ray scattering to check for radiation damage, $\mathrm{D}_{2} \mathrm{O}-$ induced aggregation, and possible effects of large internal density inhomogeneities.

\section{ACKNOWLEDGEMENTS}

We acknowledge generous financial support from the Wellcome Trust for these studies, and thank the Science and Engineering Research Council for access to the solution scattering facilities at the SRS Daresbury, ILL Grenoble and ISIS Didcot.

\section{REFERENCES}

[1] Law, S.K.A. \& Reid, K.B.M. Complement (1988) IRL Press Ltd., Oxford.

[2] Reid, K.B.M. \& Day, A.J. Immunol. Today 10 (1989) 177.

[3] Perkins, S.J., Smith, K.F. \& Nealis, A.S. Biochem. Soc. Transact. 18 (1990) 1151.

[4] Perkins, S.J., Nealis, A.S., Sutton, B.J. \& Feinstein, A. J. Mol. Biol. 221 (1991) 1345.

[5] Perkins, S.J., Smith, K.F., Kilpatrick, J.M., Volanakis, J.E. \& Sim, R.B. Biochem. J. (1993) in press.

[6] Perkins, S.J., Smith, K.F. \& Sim, R.B. Biochem. J. (1993) in press.

[7] Perkins, S.J. Eur. J. Biochem. 157 (1986) 169.

[8] Perkins, S.J., Smith, K.F., Amatayakul, S., Ashford, D., Rademacher, T.W., Dwek, R.A., Lachmann, P.J. \& Harrison, R.A. J. Mol. Biol. 214 (1990) 751. 